\title{
Essay
}

\section{Kan vi kalde det noget andet?}

\author{
Toke S. Barfod
}

Roskilde Sygehus

Toke.barfod@dadlnet.dk

Barfod, Toke S. (2015). Kan vi kalde det noget andet?, Tidsskrift for Forskning i Sygdom og Samfund, nr. 23, 53-61

Det er nu tyve år siden, jeg startede med at interessere mig for placebobegrebet og placeboeffekten. Siden har jeg primært arbejdet som hospitalslage, og $i$ ärenes lob er betydningen af de aspekter af det læagelige arbejde, som placebobegrebet dxkker over, vokset og vokset for mig. Samtidigt har placebobegrebet fäet mindre og mindre relevans. Jeg tror, at overvejelser om placebo kan skærpe vores opmærksomhed på flere vasentlige ting, der er afgørende for patienternes lidelse og behandling. Men jeg tror også, at læger af naturlige grunde ofte er tilbageholdende med at opfatte det som placebo.

- Patientens attitude og tolkning af smerte, sygdom og prognose er afgørende for graden af lidelse og bor tages alvorligt af behandleren. Placebobegrebet kan være uheldigt $i$ denne forbindelse, da det antyder, at patienten primært vil have gavn af optimistiske forestillinger om prognosen.

- At behandleren nærer omsorg for patienten er afgørende for patientens udbytte af konsultationen. Placebobegrebet kan vxre distraherende for behandleren, da det alene fokuserer på patientens oplevelse af omsorg, og ikke på behandlerens reelle mobilisering af omsorg.

- Patienten har behov for tillid til, at den bedst mulige behandling bliver institueret. Placebobegrebet antyder, at patienten primært har behov for at tro på behandlingen, hvad der kan stille sig i vejen for en balanceret information.

Placebobegrebet dxkker således efter min mening over nogle underprioriterede og ekstremt væsentlige forhold i behandlingssituationen. Betegnelsen "placebo" stiller sig imidlertid i nogen grad i vejen for, at disse forhold optimeres. 


\section{Could we call it something else?}

Twenty years ago I became interested in the concept and effects of placebo. Since then, I have mainly worked as a doctor in hospitals, but also done occasional projects on placebo. To me, the significance of the treatment factors behind the placebo effect has grown larger and larger. At the same time, the concept of placebo has lost much of its importance to me. On one hand, I do believe that reflections about placebo can strengthen our understanding of how the patient-physician encounter can affect the health of the patient. On the other hand, I believe doctors have very sound reasons to dislike contemplating on placebo.

- Doctors know that the patient's attitude and interpretation of disease and prognosis is very important to his/her degree of suffering. However, common knowledge about placebo suggests that optimistic ideas about the prognosis are the main thing to strive for, which may rightly seem a counterproductive oversimplification.

- When a health-personnel really cares about the patient, emotionally and skillfully, the patient can benefit from it in many ways. However, the placebo concept suggests, that it is the patient's subjective experience of the health-persons comfort that matters. Thus, health-personnel may not want to think about their genuine mobilization of concern as placebo, as the concept almost suggests the health-personnel just needs to pretend to care.

- The patient needs to have confidence that the best possible treatment has been selected under the current circumstances, and needs to feel comfortable with the treatment. However, usual ideas about placebo effects suggest that the patient primarily needs to believe in the positive effects of the treatment. These ideas may be unwanted by the physician, as they can disturb the physicians' focus on balanced information and on informed and wise treatment decisions.

\section{Placebobegrebet er forvirrende og effekten er vanskelig at fastslå}

Det er nu tyve år siden, jeg første gang arbejde med placebo. Jeg interviewede læger og alternative behandlere, og jeg gennemgik litteraturen (Barfod 1995; Barfod, Olesen \& Brandslund 2001). Jeg fik færten af, at placebobegrebet på to måder kan være problematisk: på grund af begrebsforvirring og på grund af at effektens størrelse er vanskelig at fastslå (Barfod 2005; Barfod 2009).

For det første kan forvirringen omkring placebobegrebet være medvirkende til, at vi overser potentielt væsentlige, helbredende aspekter af komplekse behandlingsformer (Barfod 2009). Sagen er, at begrebet både bliver brugt som synonym med "effekten af forventninger" og som samlebetegnelse for effekten af alle de 
faktorer, der følger med en kompleks behandling, men som ikke nødvendigvis er definerende for behandlingen. Det kan $\mathrm{fx}$ være effekten af den diagnostiske proces, samtalen mellem patient og behandler, berøring osv. Denne dobbelte betydning af placebobegrebet kan have afgørende indflydelse på design og fortolkning af videnskabelige (og uvidenskabelige) vurderinger af komplekse (og eventuelt uklart definerede) behandlingsformer. Man risikerer $\mathrm{fx}$ at fejlopfatte effekten af de medfølgende faktorer som blot og bart effekten af forventninger. Alternative behandlinger er ofte komplekse (og eventuelt uklart definerede). Der er al mulig grund til at undersøge effekten af alternative behandlinger videnskabeligt $\mathrm{i}$ randomiserede undersøgelser, men placebobegrebet vil ofte være mere vildledende end vejledende i denne kontekst.

Den anden vanskelighed er, at placeboeffektens størrelse ikke er let at bestemme. Selvom effekten af at modtage en "snydebehandling" under forsøgsomstændigheder er meget beskeden, kan denne forskning ikke sige noget om det helbredende potentiale i "de medfølgende behandlingsfaktorer" i klinisk praksis (Barfod 2005). Ydermere vil de samme faktorer, som skaber placeboeffekt, formentlig være fremmende for patientens efterlevelse af behandlingen, såkaldt adherence eller komplians, og kan også af den vej have afgørende positiv indflydelse på behandlingers effekt.

Disse problemstillinger optog mig meget. For de fleste læger og andre behandlere i det etablerede sundhedsvæsen er disse problemstillinger imidlertid næppe påtrængende. De fleste behandlere og læger har, ligesom jeg selv, en meget travl hverdag med patientbehandling. Jeg har de seneste år arbejdet på et mellemstort provinshospital og har ikke brugt ordet "placebo" i årevis. Jeg tror, at det skyldes nogle andre vanskelige aspekter af placebobegrebet end de ovenfor skitserede. Dem vil jeg undersøge i det følgende. Det drejer sig om placeboeffekten forstået som betydningen af forventninger, oplevet omsorg og tro på behandlingen.

\section{Placebo kan stå i vejen for effekten af sygdomsopfattelse, omsorg og tryghed}

Betegnelsen "Placeboeffekt" bruges som nævnt ofte i betydningen "effekten af forventninger", og det kan forvirre læger og andre behandlere. Sagen er, at selve placebobegrebet i denne betydning antyder, at det er bedst, hvis patienten mener, at han nok skal blive rask. Og jeg vil mene, at det, som behandleren i praksis ople- 
ver, er, at patienten har brug for en realistisk sygdomsopfattelse, der også inddrager en konstruktiv fortolkning af prognosen. Det er ikke sikkert, at patienten har behov for præcise overlevelsesstatistikker, men det virker som om, at patienten har behov for at diskussionen om fremtidsudsigterne gennemstrømmes af årvågen og individualiseret information fra behandlerens side. Patienten har brug for en omhyggelig samtale om udredningsplanen og om fortolkning og håndtering af sygdommen og symptomerne. Eftersom ordet "placebo" mere peger på en eventuel effekt af patientens positive forventninger til fremtiden, er det min tese at behandleren ofte ubevidst, men aktivt vil skubbe tanker om placeboeffekt fra sig, og i stedet arbejde på at opnå den bedst mulige kontakt og forventningsafstemning.

Noget tilsvarende kan siges om placeboeffekt forstået som "effekten af oplevet omsorg". Det er vigtigt at lægge mærke til, at "placeboeffekt" oftest ikke tolkes som "effekten af omsorg", men som effekten af oplevelsen af omsorg. Det betyder, at placebobegrebet kan virke anstødeligt på behandleren, fordi det næsten ansporer til, at behandleren făr patienten til at føle sig "taget af", uden at det nødvendigvis har grund i virkeligheden. Behandleren vil instinktivt vige tilbage fra tilskyndelsen til at "spille flink" med risiko for at sætte troværdigheden over styr. Lægen ønsker ikke at være en "placebo-læge". Den gode behandler vil snarere være optaget af at nære ægte omsorg for patientens bedste under hensyntagen til samfundets ressourcer og behandlerens emotionelle balance og sparsomme tid. Dette er en ekstremt vanskelig balance i disse tider, hvor samfundets krav og behandlingsgarantier m.v. står i kontrast til de begrænsede ressourcer i sundhedsvæsenet. Enhver behandler forsøger, så godt man kan, selv under disse vanskelige forhold, at handle i overensstemmelse med sine omsorgsfølelser for patienterne, men vil oftest vige tilbage fra at bruge ordet "placebo".

For det tredje kan placeboeffekt opfattes som synonymt med effekten af "troen på behandlingen", og også her vil behandleren ofte vige tilbage fra at søge at opnå placeboeffekt. I den videnskabeligt uddannede behandlers optik, er målet ikke, at patienten tror på behandlingen, men at patienten og behandleren sammen når frem til en realistisk vurdering af forskellige behandlingers fordele og ulemper, således at man med en vis fornemmelse af sikkerhed kan træffe et velinformeret valg. Behandleren ønsker ikke at skabe urealistiske forventninger, da de ofte blot vil lede til skuffelse og mistro overfor behandlingen, samt eventuelt mistro til behandleren og hele behandlingssystemet. Behandleren ønsker i stedet at skabe tryghed omkring behandlingsvalget, og at patienten forstår hensigten med behandlingen og dens fordele og ulemper. 


\section{"Alternative" behandlere har måske nogle særlige muligheder}

Situationen om opfattelsen af placebo kan være en anden, når det handler om "alternative" behandlinger, eller hvad man nu skal kalde dem (kompletterende eller komplementære). Alternative behandlinger vil jeg provisorisk definere som behandlinger, hvis effekt ikke er overbevisende sandsynliggjort i videnskabelige undersøgelser, og hvor forklaringsmodellerne bag deres virkninger ikke umiddelbart harmonerer med verdensbilledet i "det videnskabelige establishment". Alternative behandlinger vil af samme grund sjældent blive støttet økonomisk af det offentlige. Alternative behandlinger, der er meget dyre eller skadelige, vil formentlig oftest have kort levetid. Jeg vil derfor tillade mig at antage, at de fleste alternative behandlingsformer oftest er relativt uskadelige og ofte har en forklaringsmodel, der kan fungere sammen med et verdensbillede, der rækker ud over det videnskabelige. Jeg tillader mig også at antage, at de fleste alternative behandlere har nogle helt andre arbejdsforhold end sundhedspersoner, der er ansat af det offentlige.

Forestillingen om, at en behandling ikke er tilstrækkeligt undersøgt, eller måske slet ikke lader sig undersøge ordentligt med videnskabelige metoder, kan måske åbne op for et håb om helbredelse, som ofte kan forsvinde i de videnskabelige statistikkers diskurs. Nogle alternative behandlere vil formulere sig optimistisk overfor patienten om behandlingens effekt, mens andre kan profitere af blot at indtage en mere åben holdning. Tilsvarende vil nogle patienter "tro" på den alternative behandlings positive effekt, mens andre vil indtage en mere afventende holdning. I begge tilfælde kan det under de rette omstændigheder virke befriende for patienten og formentlig have en mærkbar positiv effekt på sygdomsopfattelse og stressniveau. Nogle alternative behandlere arbejder også langt mere bevidst og aktivt med effekten af omsorg, kærlighed og bøn, end hvad der er gængs i det etablerede sundhedsvæsen (Barfod 1995).

Min tese er altså, at alternative behandlere ofte arbejder mere aktivt med håbet om en god prognose, patientens oplevelse af omsorg og med troen på behandlingen. Allerede for tyve år siden, da jeg interviewede læger og alternative behandlere om deres brug af placebo, blev det for mig absurd at kalde det for "placebo", når fx en zoneterapeut mobiliserer kærlig omsorg gennem bøn og meditation.

Videnskabelig undersøgelse af alternativ behandling kan grundlæggende foregå efter de samme principper som undersøgelse af mere almindelige lægelige behandlingsformer (Barfod 2009). Det drejer sig om at undersøge, om det virker, og 
hvilke aspekter af behandlingen der virker. Og det drejer sig om at have en bred palet af effektmålinger, inklusive patientens oplevelse. Men ved undersøgelse af sammensatte behandlingsformer vil det ofte være uhensigtsmæssigt at kalde en evt. kontrolbehandling for "placebo", da den ofte vil indeholde terapeutisk aktive dele af behandlingen (ibid.).

\section{Hvad gør vi så?}

I forbindelse med klinisk kontrollerede forsøg kan det være meningsfuldt at skelne begrebsligt mellem fire mulige årsager til helbredelse:

- den helbredsforbedring, der kan ske også helt uden kontakt til behandleren (ofte kaldet "spontan remission")

- den effekt der kan opstå som følge af behandlingens indledende faktorer ("kontakten med behandleren", "effekten af omsorg" og "effekten af at få en meningsfuld diagnose"), som ikke kræver at en behandling iværksættes

- effekten af behandlingens medfølgende elementer (det kan fx være "effekten af at tro på behandlingen" og "selve det, at være i behandling")

- effekten af behandlingens specifikke (eller definerende) faktorer

Ofte vil det være de to midterste, der kaldes "placebo-effekt" (Barfod 2009). Den begrebslige skelnen mellem indledende og medfølgende faktorer kan være fremmende for den videnskabelige analyse af placeboeffektens videnskabelige potentiale (ibid.). Men både i videnskabelig sammenhæng og i klinisk praksis vil det oftest være bedre at benytte sig af mere specifikke termer, der knytter sig til den enkelte situation, som fx "effekten af kontakten med behandleren" eller "behandlingens symbolske virkning". Mange spørger også, hvordan man kan optimere placeboeffektens elementer i klinisk praksis (Finnis, Kaptchuk, Miller, \& Benedetti 2010), og for at besvare dette, må man være mere specifik i sit sprogbrug.

Vi skal ikke nødvendigvis afskaffe placebobegrebet, men vi bør være opmærksomme på dets flertydighed og ambivalensen omkring det.

Jeg går ud fra som givet, at det har positiv betydning for de fleste patienter, hvis de kan opnå en konstruktiv sygdomsopfattelse, hvis de oplever ægte omsorg fra deres behandlere, og hvis de føler sig trygge ved deres behandling. For mig er det ikke afgørende, om der er vist en biologisk eller overlevelsesmæssig effekt heraf i videnskabelige undersøgelser. Jeg opfatter afklaring, omsorg og tryghed som ab- 
solutter goder i deres egen ret. Hvad kan man som behandler gøre for at realisere disse goder?

De fleste behandlere gør naturligvis allerede alt, hvad de kan i denne henseende. Sundhedsvæsenets fokus på langtidsoverlevelse og effektivitet kan imidlertid i nogen grad hæmme denne bestræbelse, idet behandlernes og plejernes hverdag for manges vedkommende er præget af stor travlhed.

Fra politisk side, og fra lederne og administratorerne i sundhedsvæsenet, kunne der med fordel ske en opprioritering af mulighederne for frugtbar interaktion, samtale og kontakt mellem patient og behandler. Behovet er stort, påtrængende og sørgeligt underprioriteret. Men det vil nok ikke være fremmende for processen, hvis man formulerer, at man vil gøre det for "placeboeffektens skyld".

Den enkelte behandler vil øge sine muligheder for at bibringe patienten afklaring, omsorg og tryghed ved simpelthen at gøre sit arbejde ordentligt. Det kræver, at man er opmærksom på disse ting, at man lytter til patienten, informerer taktfuldt og præcist, at man ved, hvad man taler om og bruger sin medfølelse. Det gør de fleste behandlere allerede. Det er ikke let. Lægen og andre behandlere balancerer hver dag på en knivsæg, idet man forsøger at give patienten tid og opmærksomhed inden for en struktur, der prioriterer effektivitet og overlevelse højere end muligheden for nærvær og individualisering. Men hvad kan man gøre for at udruste behandlerne og lægerne bedre under de eksisterende forhold? Først og fremmest må vi til stadighed minde hinanden om betydningen af disse ting, mødet og kommunikationen med patienten. Herudover kan man tænke sig mange veje. Jeg vil foreslå to værktøjer: supervision og mindfulness. I Danmark har man ikke nogen stærk tradition for supervision af læger. I de fleste andre lande i verden er det almindeligt, at de yngre og de ældre læger går stuegang sammen. Det har man i Danmark fravalgt, formentlig på jantelovens, antiautoritetens, den korte arbejdstids og effektivitetens altre. Det betyder, at de yngre læger, mens de arbejder, er overladt til i ensomhed selv at udvikle den lægekunst, der vanskeligt kan læres på et universitet. Det til trods for, at supervision, feedback og vejledning med al tydelighed er vist at være fremmende for yngre lægers arbejdstilfredshed og indlæring (Farnan et al. 2012). Det andet redskab er mindfulness meditation. Kurser i mindfulness har gunstig effekt på patienters angst, stress og smerter (Goyal et al. 2014; Fjorback, Arendt, Ørnbøl, Fink \& Walach 2011). Mindfulness træning kan reducere lægers stress og udbrændthed (Krasner et al. 2009), og formentlig derigennem også patienternes sygdomsaccept og oplevelse af omsorg og tryghed ved behandlingen. 
Der er mange ting, lægen kan gøre for at afstemme patientens forventninger, øge omsorgen for patienten og fremme patientens tryghed ved behandlingen. Men jeg er personligt enig med dem der mener, at det nok ikke er optimalt at kalde det for en placeboeffekt (Verhulst 2013).

\section{Afslutning}

Det vil være godt hvis der i fremtiden kommer mere fokus på behandlerens arbejde med patientens opfattelse af sygdommen og dens prognose, omsorgen for patienten og tryghed ved behandlingen. Det kan måske bremse processen at kalde det for placebo.

\section{Taksigelse}

Tak til redaktionen og til min familie Camilla, Villiam og Felix for konstruktive kommentarer til manuskriptet.

\section{Referencer}

Barfod TS. Placebo i videnskab og behandling - litteraturstudie og kvalitativ interviewundersøgelse blandt praktiserende læger og alternative behandlere [diplo $\neg$ mop $\neg$ gave]. Århus: Institut for almen medicin, 1995: 1-214

Barfod TS, Olesen F, Brandslund I. Om Placebo og overflødige tiltag i klinisk praksis. Oversigtsartikel. Ugeskr Laeg 2001; 163:3056-9.

Barfod, TS: Placebos in medicine: placebo use is well known, placebo effect is not (letter). BMJ. 2005 Jan 1;330(7481).

Barfod TS: Evaluering når behandling er kompleks - om placebo og forskning i alternativ behandling. Tidsskrift for Forskning i Sygdom og Samfund 2009, nr. 10, side 59-78

Farnan JM, Petty LA, Georgitis E, Martin S, Chiu E, Prochaska M, \& Arora VM: The Effect of Clinical Supervision on Patient and Residency Education Outcomes - A systematic review. Acad Med. 2012;87:428-442

Finniss DG, Kaptchuk TJ, Miller F \& Benedetti F: Biological, clinical, and ethical advances of placebo eff ects. The Lancet 2010; 375: 686 -95.

Fjorback LO, Arendt M, Ørnbøl E, Fink P \& Walach H: Mindfulness-Based Stress Reduction and Mindfulness-Based Cognitive Therapy - a systematic review of randomized controlled Trials. Acta Psychiatr Scand 2011: 124: 102-119

Goyal M, Singh S, Sibinga EM, Gould NF, Rowland-Seymour A, Sharma R, Berger Z, Sleicher D, Maron DD, Shihab HM, Ranasinghe PD, Linn S, Saha S, Bass EB \& Hay- 
thornthwaite JA: Meditation programs for psychological stress and well-being: a systematic review and meta-analysis. JAMA Intern Med. 2014;174(3):357-368.

Krasner MS, Epstein RM, Beckman H, Suchman AL, Chapman B, Mooney CJ, Quill TE: Association of an educational program in mindful communication with burnout, empathy, and attitudes among primary care physicians. JAMA. 2009 Sep 23;302(12):1284-93

Verhulst J, Kramer D, Swann AC, Hale-Richlen B, Beahrs J: The Medical Alliance - From Placebo Response to Alliance Effect. J Nerv Ment Dis 2013;201: 546-52. 